\title{
FRACTURE OF ENDOSCOPICALLY PLACED FULLY COVERED METALLIC BILIARY STENT
}

\author{
Muhammad Adnan Masood, Shafqat Mehmood, Faisal Zeb \\ Department of Internal Medicine, Shaukat Khanum Memorial Cancer Hospital and Research Centre, Lahore, \\ Pakistan
}

Received: 1 January 2016 / Accepted: 10 April 2016

The fully covered biliary metallic self-expandable stents are used for relieving obstructive jaundice in patients with biliary strictures caused by benign and malignant diseases. These stents tend to relieve the biliary obstruction for longer duration in comparison with the plastic stents. To the best of our knowledge, fractured fully covered biliary metallic stent has not been reported in the literature previously and we present first case of this kind.

A 40-year-old male patient with locally advanced unresectable peri-ampullary adenocarcinoma underwent Endoscopic retrograde cholangiopancreatography (ERCP) and fully covered metallic stent insertion 9 months before this presentation. He had received palliative chemotherapy and radiotherapy for his tumour. Computed tomography abdomen to check the response of chemotherapy was done which showed progression in the disease with an increase in size of tumour. The metallic stent was patent; however, there was a significant stenosis of the bile duct just above the proximal end of the metallic stent [Figure 1]. The patient was not jaundiced and was not having any fever or pain right upper quadrant. His ERCP was performed, it showed gross distal displacement of the stent into the duodenum and the distal end of stent was found fractured. Fracture was detected by the absence of radiopaque markers on distal end [Figure 2]. Fractured stent was removed by rat tooth forceps [Figure 3], and fully covered metallic stent was inserted. The patient was discharged and referred back to primary oncologist on the same day. Endoscopic insertion of biliary stent is used for the management of biliary obstruction. The choice of using plastic or metallic stent depends on the indications of its use. ${ }^{[1,2]}$

Metallic stents are usually preferred for malignant biliary obstructions, especially, when life expectancy is

Correspondence: Muhammad Adnan Masood, Department of

Internal Medicine, Shaukat Khanum Memorial Cancer Hospital and

Research Centre, Lahore, Pakistan.

Email: dradnan1983@gmail.com

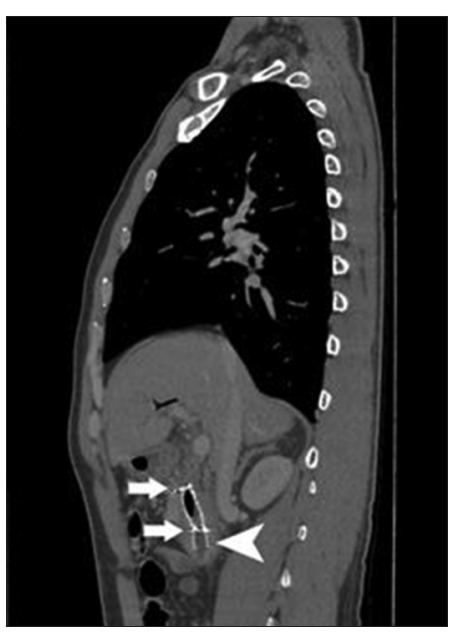

Figure 1: Computed tomography image of the fractured biliary stent: Arrows point to the markings at the proximal end and middle of the stent; Arrow head points to the absence of markings on the distal end of stent due to the fracture of distal portion of stent

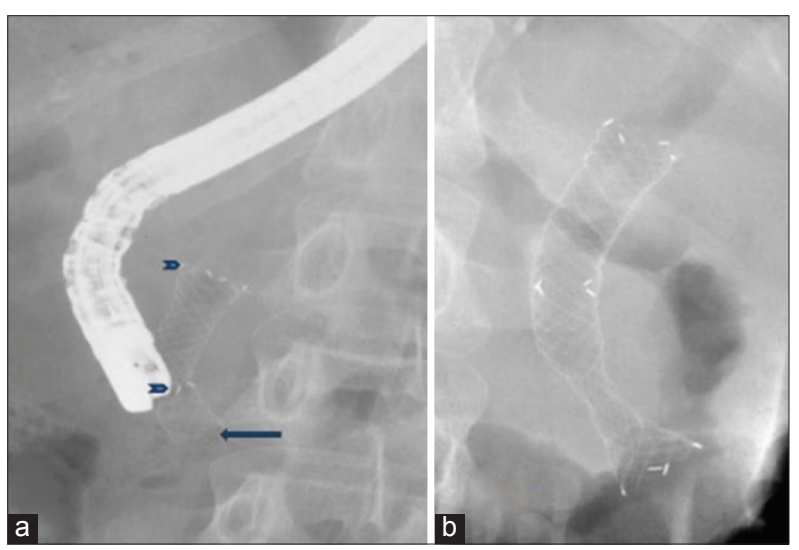

Figure 2: (a) Fluoroscopic image of biliary stent: Arrow heads point to the markings at the proximal end and middle of the stent; Arrow points to the absence of markings on the distal end of stent due to fracture of distal stent portion. (b) Fluoroscopic image of the biliary stent at the time of deployment 9 months ago, for comparison. All three markings: Proximal, middle and distal can be appreciated

$>3-6$ months. Fully covered metallic stents are relatively new development in biliary stents. These can be used in 


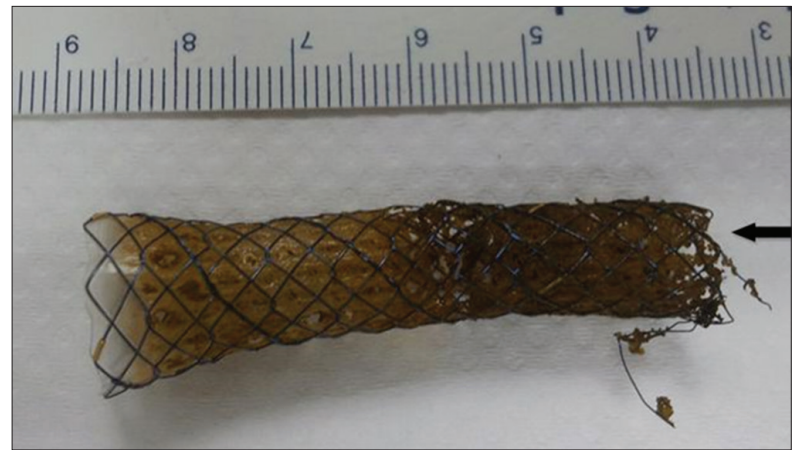

Figure 3: Fractured stent after removal. Arrow points to the fractured end of the stent

both benign and malignant causes of biliary obstruction. These have improved patency and have advantage of being removable. ${ }^{[3,4]}$ Spontaneous biliary stent fracture is very rare complication and is described in only few case reports. ${ }^{[5-10]}$ Previous case reports either describe fracture of stent placed for benign indication ${ }^{[5]}$ or for radiologically placed stents. ${ }^{[6-8]}$ Alkhiari et al. reported stent fracture at the time of removal while pulling stent. ${ }^{[9]}$

In our case, fully covered metallic stent was endoscopically placed for unresectable malignancy, spontaneously fractured before ERCP and completely removed before inserting a new stent.

Fracture of fully covered metallic biliary stent can occur very similar to uncovered stents, and though rare, this complication should also be considered in appropriate clinical scenarios while managing such cases.

\section{Conflict of Interest}

The authors declare that they have no conflict of interest.

\section{References}

1. Chun HJ, Kim ES, Hyun JJ, et al. Gastrointestinal and biliary stents. J Gastroenterol Hepatol 2010;25:234-5.

2. Lammer J, Hausegger KA, Flückiger F, et al. Common bile duct obstruction due to malignancy: Treatment with plastic versus metal stents. Radiology 1996;201:167-72.

3. Yoon WJ, Ryu JK, Yang KY, et al. A comparison of metal and plastic stents for the relief of jaundice in unresectable malignant biliary obstruction in Korea: An emphasis on cost-effectiveness in a country with a low ERCP cost. Gastrointest Endosc 2009;70:284.

4. Isayama $\mathrm{H}$, Komatsu $\mathrm{Y}$, Tsujino $\mathrm{T}$, et al. A prospective randomize study of covered versus uncovered diamond stents for the management of distal malignant biliary obstruction. Gut 2004;53:729-34.

5. Kawakubo K, Isayama H, Tsujino $\mathrm{T}$, et al. Endoscopic removal of a spontaneously fractured biliary uncovered self-expandable metal stent. Dig Endosc 2012;24:182-4.

6. Sriram PV, Ramakrishnan A, Rao GV, et al. Spontaneous fracture of a biliary self-expanding metal stent. Endoscopy 2004;36:1035-6.

7. Yoshida H, Mamada Y, Taniai N, et al. Fracture of an expandable metallic stent placed for biliary obstruction due to common bile duct carcinoma. J Nippon Med Sch 2006;73:164-8.

8. Rasmussen IC, Dahlstrand U, Sandblom G, et al. Fractures of self-expanding metallic stents in periampullary malignant biliary obstruction. Acta Radiol 2009;50:730-7.

9. Alkhiari R, Patel V, Cohen L. Spontaneous fracture of a covered self-expandable biliary metal stent and endoscopic technique for removal. Can J Gastroentrol Hepatol 2014;28:411-2.

10. Saravanan MN, Mathai V, Kapoor D, et al. Fractured metallic biliary stent causing obstruction and jejunal perforation. Asian J Endosc Surg 2013;6:234-6. 